\title{
FULLY UNDERSTANDING CONCEPT POSSESSION
}

\author{
VÍCTOR M. VERDEJO \\ Logos Research Group \\ Barcelona Institute of Analytic Philosophy (BIAP) \\ University of Barcelona \\ vmverdejo@gmail.com
}

SUMMARY: Can subjects genuinely possess concepts they do not understand fully? A simple argument can show that, on the assumption that possession conditions are taken to fully individuate concepts, this question must be answered in the negative. In this paper, I examine this negative answer as possibly articulated within Christopher Peacocke's seminal theory. I then discuss four central lines of attack to the view that possession of concepts requires full understanding. I conclude that theorists should acknowledge the existence of indefinitely many cases of genuine concept possession for partially understood concepts and therefore face the determination challenge, namely, the challenge of fully determining concept individuation from concept possession conditions of partially understood concepts.

KEY WORDS: partial understanding, concept individuation, implicit conceptions, anti-individualism, determination challenge

RESUMEN: ¿Pueden las personas poseer conceptos que no comprenden completamente? Un argumento simple muestra que, si las condiciones de posesión individúan conceptos totalmente, la respuesta a esta cuestión es negativa. En este artículo, examino esta respuesta con base en una posible articulación de la teoría de Christopher Peacocke y presento cuatro líneas centrales de ataque a la idea de que la posesión de conceptos requiere compresión completa. Concluyo que debemos reconocer la existencia de un número ilimitado de casos de posesión genuina de conceptos parcialmente comprendidos y así afrontar el reto de la determinación, esto es, el reto de determinar totalmente la individuación de conceptos a partir de condiciones de posesión de conceptos parcialmente comprendidos.

PALABRAS CLAVE: comprensión parcial, individuación de conceptos, concepción implícita, antiindividualismo, reto de la determinación

Can subjects genuinely possess concepts they do not understand fully or of which they lack full mastery? There are many ways in which this crucial question may receive an answer. In this paper, I am exclusively concerned with an assessment of it from the point of view of the family of theories that assume that possession conditions fully individuate concepts. The qualification "fully" in this context is somewhat redundant since, for any $X$, we do not strictly speaking individuate $X$ if we do not do so fully. Now, a simple argument can show that, for these theories, the answer to our starting question must lie in the negative. Unsurprisingly then, and as we will see in detail below, Christopher Peacocke, one of the most illustrious proponents 
of concept individuation via possession conditions, has given explicit credence to the negative view.

In this paper, I endeavor to show that, even when stated within the robust framework of Peacocke's theory, this negative answer is clearly wrong and must be rejected in favor of a positive answer. The negative answer, it must be noted for the record, corresponds to one of the horns of the dilemma unveiled in Verdejo and de Donato 2015 for theorists of concept possession: either they accept possession conditions for partially understood concepts - and hence possession conditions are not concept-individuating - or else they do not - and hence possession conditions are arguably conceptindividuating but unlikely constricted. I here therefore propose that it is the former horn - the positive answer to our starting questionthat theorists of concept possession are well-advised to underwrite. However, in a way to be specified at the end of this paper, this option inescapably involves challenging implications for the whole project of constructing a theory based on concept-individuating possession conditions. This piece thus both amends and complements Verdejo and de Donato 2015. It amends it because in that paper not enough is done by way of articulating the most plausible versions of the view that one only possesses fully understood concepts and, hence, to bring out all the reasons that may bear on its rejection. It complements it because, as it stands, the dilemma leaves the theorist of concept possession to guess what the most plausible route is and what challenge it exactly poses. This is a gap I set out to fill in what follows.

Several tasks are targeted along the way ahead. After making explicit the relevant terminology (Section 1), I will lay out the simple argument for the full-understanding view of concept possession (Section 2). This argument suggests that this is probably a widespread view in the theorizing about concepts in terms of concept possession. I will go on to state the precise way in which the full-understanding view can be shaped within Christopher Peacocke's seminal and longstanding theory (Section 3). After the central thesis for the fullunderstanding view is carefully stated, I will offer (Sections 4-7) a series of arguments that support, on the contrary, a positive answer to our starting question. The arguments run to the conclusion that full understanding is not constitutive of genuine concept possession. It is the main conjecture of this paper that, if the considerations of these sections are sound and affect paradigmatic cases of concept possession, a substantial revision of current views on concepts is called for. An important part of this revision would consist in facing 
what I will call the determination challenge in the theory of concept possession (Section 8).

\section{Concept Possession and (Full) Understanding}

Before we proceed, it is vital to make explicit how I shall be using the terms of the discussion to follow. First, for a subject $S$ to possess a concept $C$ is for $S$ to fulfil $C^{\prime}$ 's possession conditions, whatever exactly these possession conditions turn out to be. Here I use the expressions "possessing $C$ " and "having $C$ " interchangeably. Thus, for $S$ to have $C$ is for $S$ to fulfil $C$ 's possession conditions. Unless otherwise specified, possession is here always meant to be genuine as opposed to metaphorical or non-literal: the target possession conditions involve an all-or-nothing and actually satisfiable kind of condition. Thus, for any actual $S, S$ either possesses $C$ or doesn't. For instance, a baseline and uncontroversial necessary condition for the possession of any given concept $C$ is to be able to think of $C \mathrm{~s}$ or of whatever falls under $C$ as such (cf. Fodor 1998, 2004; Davis 2005a, 2005b). Relatedly, the fact that $S$ is able to think (or have any attitude) that $p$ implies that $S$ has or possesses whatever are the constituent concepts of the thought that $p$. On this standard reading, concepts are therefore the constituents of thoughts, and hence subjects do not think or have attitudes towards propositions without having the corresponding constituent concepts.

In this context, it is crucial to distinguish possession of $C$ from what I will be calling understanding or grasp or mastery of $C$. I follow well-established practice (e.g. Burge 1979, Peacocke 1992, Brown 2000, Wikforss 2008) in using "understanding" for the thing some other authors prefer to call "conception" (e.g. Bealer 1998, Goldberg 2002, Higginbotham 1998, Rey 1998). ${ }^{1}$ Here I will adopt the usual and largely neutral way of conceiving of understanding in epistemic terms. More precisely, in what follows, for $S$ to understand $C$ is for $S$ to know the content of $C$-whatever exactly the preferred notion of content is.

${ }^{1}$ In my view, "understanding" is a more accurate term because, unlike "conception of $C$ " or "possession of the/a conception of $C$ ", "understanding of $C$ " immediately suggests an epistemological dimension (crucial to distinguish this notion from strict possession of $C$ ) and also because, unlike "conception of $C$ ", "understanding of $C$ " does better in preventing an interpretation of this epistemological dimension in terms of a meta-conceptual or second order relation (between subjects and their concepts). The discussion in the main text is however entirely unaffected by this terminological issue. 
Importantly, the notion of knowledge at stake in the elucidation of understanding need not be, and generally is not a form of conscious or explicit knowledge (Higginbotham 1998; Peacocke 1998, 2008, chap. 4). Authors usually agree that for $S$ to understand $C, S$ need not consciously access the content of $C$ or be capable of expressing properly the content of $C$. Similarly, the knowledge in question need not be understood as a kind of meta-knowledge or self-knowledge of concepts one possesses. At least since Burge 1988, it is clear that theorists may separate issues about self-knowledge of concepts or conceptual contents from issues of understanding. Indeed, the fact that $S$ understands $C$ is not to be assimilated to the fact that $S$ knows or has an epistemic relation towards $C$ itself but only to knowing whatever makes $S$ count as understanding $C$, typically, the subject matter of $C$ or that to which $C$ applies (cf. Martí 1998, pp. 164-165; Wikforss 2008, pp. 408-409).

We finally reach the key notion of full mastery. For present purposes, for $S$ to have full mastery, full understanding, a full conception or simply mastery of a concept $C$, is for $S$ to have comprehensive or complete knowledge of $C$ 's content, however exactly this content might be stated. The expression "comprehensive knowledge" is somewhat vague. It is likely that determining the comprehensive or complete character of a given knowledge of content requires reference to a context-sensitive standard. The discussion to follow is inevitably marked by the fact that for most concepts it is unclear what this standard is or what precisely it amounts to. In any case, and as Davis has pointed out, if full concept mastery is humanly possible, then "one thing we can say with confidence is that the relevant standard must be something short of omniscience about the subject [matter]" (2005b, p. 319). At some points, as I will explicitly indicate, I will use "full mastery of $C$ " so as to refer to the standard knowledge of the content of $C$ exhibited by the experts or those most knowledgeable in the subject matter of $C$.

On this picture, generally, subjects do not understand a concept $C$ unless they possess $C$. Obviously, to understand $C$ implies being capable of employing $C$ in thought and one does not employ concepts in this sense without having or possessing them. On the other hand, for expository purposes, I will be assuming that if $S$ does not understand $C$ at all, that is to say, if $S$ is completely ignorant of the content of $C$, then $S$ does not possess $C$. This assumption may be rejected when interpreted as a constitutive condition in the light of non-epistemic accounts of concept possession. But the assumption is largely uncontroversial as a contingent condition on concept possession and it 
is worth holding to it for present expository purposes. Thus, I will assume that, as a matter of contingent fact (in the actual world), one does not possess $C$ unless one meets some (however minimal) epistemic condition regarding the content of $C$.

That said, in the context of this discussion, it is a possibility -indeed the possibility to be examined in this paper - that a subject $S$ possesses $C$ whereas $S$ does not fully understand or misunderstands or partially (mis)understands $C$. As we will see, this possibility has been approached in a number of ways in the literature. A baseline characterization says that for $S$ to misunderstand or partially (mis)understand $C$ is for $S$ to lack knowledge of the content of $C$ to the extent that $S$ may systematically incur in conceptual errors in the employment of $C .^{2}$ The errors are conceptual in that they do not depend on the lack of specific empirical information (beyond that required for acquisition of the concept). Typically, they are errors consisting in the wrong application of the concept, i.e. cases in which one judges or believes that $x$ is $C$ when $x$ is in fact not $C$. To illustrate, if in normal conditions I systematically judge (or potentially would judge) that the table is blue when it is in fact yellow, and I do so on the basis of my (yellow-like) perceptual experience (and not say, on the basis of testimony or pure guessing), then I would be incurring in a conceptual error of the required sort.

$S$ misunderstanding $C$ must be sharply distinguished from $S$ incurring in a form of irrationality. From a roughly Fregean and widely shared perspective, concepts are "constitutively and definitionally tied to rationality" (Peacocke 2008, p. 60). Irrationality is therefore usually excluded from the account of concept possession (Wedgwood 2007, pp. 168-169). Patently, irrational subjects or subjects that exhibit irrationality may incur in all sorts of mistakes and misunderstandings in their employment of a concept but this is hardly a matter of interest regarding the nature of concepts and concept possession. The target partial (mis)understanding here examined is thus one in which subjects make conceptual errors stemming only from a deficient knowledge of the (content of the) target concepts and not from defects of rationality.

${ }^{2}$ See also Verdejo and de Donato 2015. Strictly speaking, therefore, misunderstanding $C$-i.e. wrong application of $C$ - should be distinguished from agnosticism about $C$-i.e. suspending judgment or being unsure about the application of $C$ (Brown 2000, p. 661, 2004, p. 295). 


\section{Full Understanding, the General View}

The view under scrutiny in this paper can be initially characterized in terms of (1) for any subject $S$ and concept $C$ :

(1) For $S$ to meet the conditions for possessing $C$ is for $S$ to meet the conditions for fully understanding or mastering $C$.

It follows from (1) that $S$ cannot be said to possess $C$ unless $S$ fully masters or understands $C$. As we will see in detail, this is a thesis once explicitly held by Christopher Peacocke, who for several decades has championed the view that possession conditions individuate concepts or, in other words, are the defining and explanatory conditions that make a concept be the concept it is (Peacocke 1983, 1989, 1992, 1997, $1999,2004)$. However, sympathy to and endorsement of the view that possession conditions individuate concepts goes without saying in much of the work of scholars who defend a version of so-called Inferential Role Semantics (IRS), that is to say, theories that offer accounts of concept-individuating contents in terms of inferential roles (Verdejo and de Donato 2015, pp. 153-154). On the assumption that inferential roles do individuate contents, and that contents, in turn, individuate concepts, $C$-individuating inferential roles serve to specify what is required for a subject $S$ to possess the concept $C$. It is thus natural for all the theories falling under the head of IRS - a mark of the reflection on concepts in the 20th century according to Fodor (2004) - to subscribe to (2), for any $S$ and $C$ :

(2) To say what individuates $C$ is to say what it takes for $S$ to have or possess $C$.

Two assumptions bring out the connection between (1) and (2). On the one hand, there is the already mentioned, widespread assumption that conceptual contents individuate concepts. On the other hand, we find the assumption that possession conditions just are or determine understanding conditions, where understanding is a kind of knowledge of conceptual content (see Section 1). The simple general argument linking (1) and (2) can therefore be stated as follows:

(i) Premise: Possession conditions are conditions on understanding or knowing concept-individuating content.

(ii) Premise: Possession conditions individuate concepts — by (2).

(iii) Conditions on understanding individuate concepts — by (ii), (i) and substitution. 
Conclusion: Conditions on full understanding fully individuate concepts - by (iii) and self-evident mereological relation.

The argument shows that (1) is self-evident when possession conditions are concept-individuating understanding conditions. Only full understanding conditions provide full individuation - that is to say, individuation properly so-called - for the proponents of conceptindividuating possession conditions (see Verdejo and de Donato 2015 for a variation on this line of reasoning).

\section{Full Understanding, on Peacocke's Framework}

The foregoing argument makes plausible the idea that (1), or a thesis in the vicinity of (1), is held by a prominent tradition of authors proposing accounts of concepts in terms of concept possession. Having said that, in this paper I will only aim at what it is fair to regard as the most elaborated version of (1) in the literature: Christopher Peacocke's. If my criticism succeeds in the most elaborated case, the suggestion goes, other approaches that endorse the thesis would seem to be equally vulnerable. Needless to say, Christopher Peacocke's thinking is much richer and more complex than I can make out here and the present discussion should not be read as an objection or amendment to his views. Furthermore, Peacocke's more recent developments seem to have moved away from earlier statements concerning (1) over the 1990s and early 2000s, which are the concern of this paper. ${ }^{3}$ In what follows, nonetheless, I shall confine attention to those Peacockean tenets that give explicit credence and can be used to spell out thoroughly the view that concept possession involves or amounts to full concept mastery. A particularly clear example is found, for instance, early in A Study of Concepts, when Peacocke introduces the so-called Principle of Dependence:

There can be nothing more to the nature of a concept than is determined by a correct account of the capacity of a thinker who has

${ }^{3}$ More recently, Peacocke seems to admit the possibility of concept possession with only partial understanding or grasp (e.g. Peacocke 2008, pp. 290-297; Peacocke 2014 , p. 84). I lack space in this paper to tackle rigorously and fully the evolution of Peacocke's views outside endorsement of (1) and, more generally, outside the boundaries of approaches in terms of possession conditions. All the same, this discussion targets explicit and clear claims about full understanding and conceptindividuating possession in the literature which are of interest in their own right and, as defended in the previous section, representative of a prominent branch in the philosophy of mind. 
mastered the concept to have propositional attitudes containing that concept (Peacocke 1992, p. 5).

The foundational principle of dependence promotes accounts of concepts in terms of the conditions of concept mastery. Patently, concept mastery is in this case to be interpreted in terms of full concept mastery or understanding. This is made explicit only a few pages later, in a discussion of a counterexample against his propounded possession conditions for red (Peacocke 1992, pp. 27-33). Peacocke observes that even if a sense can be made of concept-attribution in cases of partial (mis)understanding, proper accounts of concepts in terms of possession conditions exclusively concern cases of full mastery of the concept. The point reappears explicitly in a discussion of Dummett's views on the linguistic dependence of concepts (Peacocke 1997, p. 13). ${ }^{4}$

On Peacocke's account, therefore, genuine possession conditions are conditions of full mastery, just as (1) states. Like any notion of full understanding or concept mastery, however, Peacocke's notion requires a certain standard of comprehensive knowledge of the content of $C$ (see Section 1 above). At several places throughout his work, Peacocke offers a precise way of stating mastery constitutive of possession when he contends that to possess a concept amounts to having knowledge of the condition for something to be the reference of the concept or, as he also puts it, interchangeably, knowledge of the fundamental reference rule for the concept (Peacocke 1992, p. 23; 2004, p. 96; 2008, p. 3, 2012, p. 222).

Clearly, comprehensive knowledge of the condition for something to be the reference of $C$ (i.e. knowledge of the fundamental reference rule for $C$ ), as opposed to comprehensive knowledge of the reference of $C$, need not involve knowledge of the condition for something to be the reference of some other concept $C^{\prime}$, even if $C$ and $C^{\prime}$ co-refer. Thus, for instance, for $S$ to know the condition that something has to meet to be the semantic value of square-shaped is not for $S$ to know the condition that it has to meet to be the semantic value of regular diamond-shaped, even if it is true that objects fulfil the condition to be the semantic value of square-shaped just in case they fulfil the condition to be the semantic value of regular diamondshaped (cf. Peacocke 1992, pp. 74-76).

\footnotetext{
${ }^{4}$ This point serves to introduce the distinction between possession conditions and attribution conditions to be tabled in Section 6 .
} 
It seems fair to suppose that one way in which this notion of full mastery is made fully explicit, and can thus also be assessed, is in terms of the particular Peacockean accounts of concept possession he has offered so far. Particular instances of possession conditions for a target concept $C$ instantiate, therefore, accounts that respect (4), for any $S$ and $C$ :

(4) For $S$ to meet the conditions for possessing $C$ is for $S$ to fully know what it is for something to be the semantic value of $C$ (or the fundamental reference rule for $C$ ).

Although it departs from Peacocke's literal use, I license the word "fully" in (4) to make totally clear that (4) is an articulation of (1) above, and to distinguish sharply (4) from a reading of (1) that allows for partial (mis-)understanding (see $\left(4^{\prime}\right)$ in Section 8 below). In the following sections, I will argue that the notion of concept possession expressed by (4) faces challenging and eventually fatal problems. These problems can be laid out in terms of problems about its necessity (Sections 4, 5 and 6) and its sufficiency (Section 7).

\section{Implicit Misunderstanding}

As noted, according to Peacocke, concepts are individuated at the level of Fregean sense. Peacocke's theory of concepts exhibits a further commitment to a celebrated Fregean view. This view, which informs above all Frege's late mathematical thinking, can be stated thus: a subject may grasp a sense in spite of not grasping it clearly or sharply (e.g. Frege 1914). Burge (1990) has argued at length that the correct way of interpreting Frege's contention is by acknowledging that senses are not linguistic meanings. Unlike linguistic meanings, so Burge reasons, senses must be distinguished from people's understanding of them as expressed in the public language. In a way that he takes to be congenial to Burge's developments, Peacocke tries to capture the Fregean dictum by introducing the notion of implicit conception, i.e., informational states sufficient for possession of the concept which do not involve explicit knowledge of the content of the concept.

In several writings (1998, 2000, 2008, esp. chap. 4), Peacocke defends the existence and explanatory importance of implicit conceptions. According to Peacocke, for instance, both Leibniz and Newton non-deferentially possessed the concept limit in virtue of their both having an implicit conception. This implicit conception was arguably not made explicit until more than a century later, with the work 
of Weierstrass. Nonetheless, we can fairly attribute to Newton and Leibniz the mathematical concept limit since, unlike their contemporaries, Newton and Leibniz achieved the sort of abilities that would have made it possible for them to understand Weierstrass's epsilondelta definition and to recognize it to be true. Attribution of an implicit conception of limit is therefore what explains Newton's and Leibniz's abilities regarding their correct judgments and reasoning about limits.

As is plain, to have an implicit conception of $C$ is one prominent way in which subjects may, according to Peacocke, possess $C$. The notion of possession at stake here is in accordance with (4) above. Having an implicit conception of $C$ is a way of having knowledge of the condition for something to be the semantic value of $C$ (Peacocke 2004, p. 96).

It might seem plausible, at first pass, that implicit conceptions only concern the conscious or explicit view of one's concepts and thus leave untouched any thesis about its relation to our understanding or conceptions (e.g. Higginbotham 1998, p. 151). Peacocke's consideration of the limit case suggests precisely this neutral interpretation. After all, it is reasonable to suppose that Newton and Leibniz did have a full understanding of limit. In other words, it is not at all clear that they incurred in the sort of conceptual errors that would constitute misunderstanding concerning the concept and typically result in its misapplication (see Section 1 above for the target notion of misunderstanding).

Note, however, that Frege's own considerations do not go in just this direction. Frege's introduction of the distinction between grasping a definite sense and grasping it sharply is often made in the context of vehement denunciations of important sorts of misunderstanding. Ironically, this is clear in the case of his discussion of Weierstrass's understanding of number. For instance, Frege complains that Weierstrass worked with a "very unclear" notion of number so that he "fails to see that what he asserted does not follow from his definition, but from his inkling of what number is" and thus "involves himself in contradictions and yet arrives at true thoughts, which one must admit, come into his mind in a purely haphazard way" (Frege 1914, pp. 221-222). Weierstrass grasped the definite sense of "number" but he failed to do so sharply or clearly. The consequence is that, according to Frege, we can attribute to Weierstrass a serious sort of misunderstanding in the relevant sense, one which led him to contradictions and invalid inferences and which seem to 
count as a deficient knowledge of what it is for something to be the semantic value of number. This seems to put (4) in jeopardy.

One may find the focus on Frege's observations beside the point. We may not, after all, accept his example as involving attribution to Weierstrass of a Peacockean implicit conception for the concept number. While this is true, note that implicit conceptions are meant to actually capture and explain Frege's distinction between grasp and sharp grasp of a sense (Peacocke 1998, p. 50, Peacocke 2008, p. 121). In this context, to renounce a neat match between Frege's explicit remarks and the notion of implicit conception seems to undermine the motivation to bring forward the notion in the first place.

We may however move on to look upon other plausible cases of implicit conceptions in empirical research. For instance, John Dalton's concept of atom, just like Leibniz and Newton's concept of limit, is a non-deferential case of concept possession in that Dalton was the theorist that, at the time, achieved the best understanding of the concept. Dalton's abilities in reasoning about atoms would be explained, by the same token, by possession of an implicit conception whose exact definition was given only with subsequent developments. As is known, however, Dalton believed that atoms are indivisible. In so doing, he plausibly incurred in a conceptual error constitutive of misunderstanding of atom.

Now, one may hesitate to grant that Dalton, even if arguably the founding father of atomic theory, had an implicit conception for atom as opposed to an implicit conception for a different concept or no concept at all. There are reasons to ease this hesitation. First, the suggestion that Dalton possessed an implicit conception for a different concept or no concept at all seems to have disastrous consequences for the publicity of concepts: if a single false belief or presupposition - viz. the false belief that atoms are indivisible - grants the postulation of different concepts or the denial of concept possession, we would turn out to have very few concepts we share with others (I shall come back to this set of issues in Section 7). Second, as I have argued elsewhere at length, we seem to want to claim that contemporary thinkers - whether experts or non-experts - disagree with Dalton over the divisibility of atoms. But the necessary common conceptual ground for disagreement would be irremediably lost had Dalton turned out to employ a different concept or no concept at all when thinking about atoms (Verdejo 2016, see also Burge 1986, p. 716). These undesired results back our initial intuition that the founding father of atomic theory, as arguably Dalton was, likely possessed the concept of atom. 
Now, similar considerations can be raised in the case of ordinary, non-mathematical and non-theoretical concepts. Implicit conceptions allegedly explain possession of these concepts, such as chair (cf. Peacocke 1998, 2008). But if $S$ has chair in virtue of having an implicit conception of chair, it is plausible, and certainly conceivable, that wrong information about chairs enters $S$ 's implicit conception. $S$ may thus systematically misapply chair in a number of cases. For instance, $S$ may systematically judge or believe that sofas are chairs or that three-legged chairs are not really chairs. Generally, it would seem, $S$ may have false or incorrect beliefs concerning $C$ in his implicit conception of $C$. This is a possibility acknowledged by Peacocke himself:

It is not impossible for there to be an implicit conception with an incorrect content. A thinker may misunderstand some word in the public language, in which case the implicit conception may have a false content about the word. False presuppositions about certain kinds of object or event in his environment may also enter the content of his implicit conceptions. (Peacocke 2008, pp. 141-142)

One may object that the kind of misunderstanding under consideration in this quote may be precisely a misunderstanding about the relevant word - viz. "chair" - without involving any misunderstanding of the concept - viz. chair- leaving thus untouched the claim to full understanding. In reply, I should note that this interpretation seems implausible when, as Peacocke explicitly concedes in the quoted paragraph, the false contents in the implicit conception may include "false presuppositions about certain kinds of object or event in the environment". This is precisely the case in point from the example above. Suppose I have an implicit conception for chair which includes the false presupposition that sofas are also chairs. This is a false presupposition about objects in the world - viz. chairs - as opposed to words — viz. "chair" — which will lead me to systematically misapply the concept chair to sofas. This situation would involve misunderstanding of chair in the relevant sense. This interpretation also receives support from Peacocke's remark that "there is a core of cases in which one can expect that the content of the implicit conceptions within that core will be correct" (Peacocke 2008, p. 142). This proviso makes sense only if correctness in core cases determines possession of a concept as set against potential incorrectness in non-core cases. Implicit conceptions may therefore involve partial misunderstanding of a possessed concept $C$. This misunderstanding 
would, contra (4), amount to only partial knowledge of the condition for something to fall under the concept.

\section{Too Demanding Possession Conditions}

Leaving aside implicit conceptions, there are reasons to suppose that concept-individuating possession conditions that respect (4) are too demanding for the person in the street. Peacocke's most discussed possession conditions concern concepts for which (4) might seem to be in good standing, such as logical or perceptually basic concepts. They also include self-referential concepts or meta-concepts. Here, I would like to stress, first, the particularly problematic case of natural kind concepts.

It is difficult to say what it takes for $S$ to possess full mastery of a natural kind concept $K$. On the one hand, many of our ordinary concepts are natural kind concepts, and thus their possession must be, apparently, a common feature of the layman. However, unlike other sorts of concepts, natural kind concepts apply to subject matters whose nature may be, even if elementary for the expert, largely unknown to the ordinary thinker.

Consider the concept animal. If, as (4) requires, possession of animal involves full knowledge of the condition for something to be the semantic value of animal, then it would seem that only biologists or experts in the field of biology are our candidates for possession. The ordinary, non-expert thinker is, for indefinitely many creatures or organisms, certainly ignorant of what it is for them to be the semantic value of animal. For instance, sponges (phylum porifera) are animals. It does not seem controversial to suppose that many people in the street ignore this fact. To that extent at least, they will clearly lack full knowledge of what it is for something to fall under animal. Should we then declare that the ordinary, non-expert thinker lacks the concept animal? This is intuitively implausible provided that animal seems an ordinary concept accessible to one and all from a very tender age. A similar problem can easily be made to arise for a huge variety of other natural kind concepts.

This alone can hardly be an argument against (4). After all, one may deny that ordinary thinkers literally possess natural kind concepts and explain away attribution of the concept to the layman by invoking conditions that are not possession conditions. I shall return to this move in Section 6 below. Here, I would like to consider a different way out of the problem suggested by Peacocke himself. Many natural kind concepts are partially recognitional but, even in 
these cases, it seems fair to suppose that their possession conditions go beyond purely recognitional or observational conditions. According to Peacocke, these conditions must accommodate the fact that application of the concept requires sameness of kind in regard of previous encountered instances.

A plausible possession condition for one sort of natural-kind concept, a sort that includes the way we think of water, will include a clause stating, roughly, that from the premise that something falls under the concept, the thinker is willing to infer that it is of the same underlying kind as certain samples he has encountered. (Peacocke 1992, p. 26; see also the remarks about horse in Peacocke 1992, p. 144.)

Consider the concept flower. Following Peacocke's suggestion, (4) requires of a flower-possessor full knowledge of what it is for something to be the semantic value of flower in the specific sense of knowing that the application of flower is restricted to the flower kind or, as Peacocke claims, knowledge that "for any object in the universe, it is a flower if and only if it is of the same botanical kind as those he can recognize" (Peacocke 2004, p. 91). Clearly, unlike a purely recognitional condition, Peacocke's propounded condition would not be undermined in cases in which $S$ fails to know that something, say saffron, is a flower. For $S$ can still be said to know that something is a flower just in case it is of the same botanical kind as the roses, daisies and lilies $S$ has encountered before.

This strategy does not lead us very far however. The condition that $S$ knows that, for any natural kind concept $K$ and object $x$, $x$ is $K$ just in case $x$ is of the same kind as known $K \mathrm{~s}$ is hardly informative or concept-individuating. Crucially, on the assumption that $S$ knows that $K$ is a natural kind concept, it would seem that the condition applies whether or not $S$ possesses $K$. The young student of biology might be introduced for the first time to some pictures or drawings of amphibians (say, some frogs) and be told that they are amphibians. As a consequence of this, she might be said to know that something falls under amphibian just in case it is of the same kind as those frogs she can recognize. Having this knowledge cannot be the whole story about what it takes to possess amphibian. Clearly, at this preliminary stage, such knowledge does not suffice for full individuating knowledge of what the condition is for falling under $K$ or even substantive positive knowledge of the nature of $K \mathrm{~s}$.

The situation is probably worse than the foregoing considerations suggest. For even on the safest reading of knowledge of the con- 
dition for something to be the reference of $K$, that is to say, even when we consider that such knowledge is expert knowledge, the target knowledge might not be sufficient for full understanding. This can be illustrated, again, with the concept of atom. I have earlier suggested that it seems fair to suppose that, since Dalton was the founding father of atomic theory, he possessed the concept of atom (Section 4). Dalton's knowledge about atoms was, at his time, clearly expert knowledge. Nonetheless, Dalton also patently misunderstood the concept. He famously wrongly believed that atoms were indivisible. He therefore misapplied atom in systematic ways. If this is correct, in at least some cases, we may have possession and expert knowledge of $C$ and yet fall short of full understanding of $C$.

Someone might wish to reply that a charitable reading of (4) would force us to exclude natural kind concepts from its range of application. After all, it might be submitted, Peacocke has not given any clear statement of the application of (4) to such cases, and they might then be seen as special cases for which full understanding is not really possible or easily describable. Remarkably, however, the charge that Peacockean possession conditions are too demanding can be raised even when full understanding seems most natural or secured. Davis (2005b) for instance has shown that Peacocke's account of possession for observational concepts can be seen to rely on an implausible "orthosensory recognition condition" (Davis 2005b, p. 297), that is to say, a condition that demands application of the observational concept $F$ to objects on the ground that they look $F$ (when subjects take experience at face value) (cf. Peacocke 1999, p. 16). However, this general condition is compromised by a good number of counterexamples (cf. Davis 2005b, pp. 292-305). For instance, a subject $S$ that possesses red may wear green sunglasses. After some time of adaptation, $S$ would correctly judge things to be red (and refrain from judging them to be green) in spite of things looking green to him. The orthosensory recognition condition clearly fails for red, which suggests that it should be discarded as a necessary possession condition for observational concepts.

Similar problems appear to infect other cases in which the necessity of Peacocke's possession conditions can be called into question. These include logical concepts (e.g. Davis 2005a, pp. 148-152) and modal concepts (e.g. Roca-Royes 2010, pp. 352-358). In sum, if Peacocke's propounded possession conditions are good specifications of (4), then the thesis is embarrassed by the existence of counterexamples in which thinkers are implausibly deprived of their concepts. 


\section{Anti-Individualism about Concept Possession}

It must be acknowledged upfront that Peacocke's possession conditions are not, or not necessarily, individualistic. In particular, "a possession condition may have features which ensure that a thinker's satisfaction of it depends in part on his relations to his environment" (Peacocke 1997, p. 14). Accordingly, there certainly are conditions appropriate to full understanding that ratify the anti-individualist principal thesis that what concepts a subject has constitutively depends upon the (physical or social) environment. However, antiindividualism seems to also involve cases of misunderstanding of genuinely possessed concepts incompatibly with (4). Here, I would like to stick to the most central version of anti-individualism as defended by its leading proponent Tyler Burge (1979, 2007b). Although there are alternative formulations of anti-individualism, ${ }^{5}$ standard anti-individualistic scenarios centrally involve subjects that misunderstand and even seriously misunderstand their concepts.

Consider the classic arthritis-case. A medically ignorant subject, call him Bert, is in a linguistic community very much like our own. Bert believes that he has arthritis in his thigh. Bert misunderstands arthritis in a very clear way. He systematically misapplies arthritis by ignoring the fact that arthritis is a disease of joints only. Since Bert's community is like our own and he is willing to accept the community's authority, Bert is said to believe, wrongly, that he has arthritis in his thigh - as opposed to believing, correctly, that he has a different disease, say, tharthritis, in his thigh. The lesson of anti-individualism is that the concepts and thoughts we attribute to Bert are constitutively dependent upon the community to which he belongs. In the context of our discussion, the very straightforward lesson to draw is that if anti-individualism is true, then (4) cannot be. Bert is fundamentally ignorant of the content of arthritis. He cannot be said to have knowledge, let alone full knowledge, of the condition for something to be the semantic value of arthritis. Nonetheless, if anti-individualism is true, we must attribute arthritis to Bert.

It might be tempting for the defender of (4) to take up on Peacocke's own way of dealing with anti-individualism (Peacocke 1992, pp. 27-33; 1997, pp. 12-14). Peacocke is well aware of the problem that standard cases of anti-individualism may pose to his theory. Anti-individualism involves scenarios where subjects are attributed

\footnotetext{
${ }^{5}$ Alternative formulations that do not appeal to cases of misunderstanding may concern, for instance, non-standard theory (Burge 1986), testimony (Goldberg 2009) or representational traditions (Schroeter 2008).
} 
concepts even if the relevant Peacockean possession conditions are not fulfilled. For instance, a thinker who is attributed red but misunderstands the concept to the extent that he fails to apply red when perceptually confronted, in normal conditions, with a shade of dark red would fail to meet the possession condition for the concept. Peacocke's propounded solution is to introduce the distinction between attribution and possession conditions. According to Peacocke, anti-individualism concerns only attribution conditions, that is to say, conditions on the truth of reports of the form " $x$ believes that $w \quad$ "such as "Bert believes that he has arthritis in his thigh" (Peacocke 1992, p. 29; 1997, p. 13). The truth conditions concern linguistic meaning or word usage in certain deference-dependent circumstances. On Peacocke's account, therefore, anti-individualism is (or is primarily) a linguistic issue since "while possession conditions are given for concepts, attribution conditions and deferencedependence primarily concern words and sentences" (Peacocke 1992, p. 30).

Peacocke's outlined view is a perfectly coherent position but it does not make (4) compatible with anti-individualism. For the proper (although perhaps not the only) locus of anti-individualism is not really linguistic meaning or even mental content but thought and (concept-individuating) possession conditions. On the one hand, thought and attitude attribution in anti-individualistic accounts must be understood, according to Burge, as "characterizing the person" (Burge 1979, p. 103) or "a person's epistemic perspective" (p. 103) or "a person's intentional mental states or events" (p. 104). Indeed, the thought experiments by which anti-individualism was introduced in Burge's 1979 paper involve counterfactual situations that show that two subjects with exactly the same individualistic conditions are subjects that can have different concepts. As Burge has made explicit more recently, when we claim, in anti-individualistic contexts, that $S$ has $C$ (or a $C$-containing belief) we do not appeal to a sui generis, merely linguistic, sort of concept possession. The claim is rather about "constitutive or essential conditions of an individual's having the kinds of mental states and events that the individual has" (Burge 2007b, pp. 155-156).

One may suggest at this point that, under a weaker interpretation of anti-individualism, attributions of a concept $C$ in deferencedependent belief reports may be conceived as involving a notion of having attitudes towards a content containing $C$ that falls short 
of genuine concept possession but is also not merely linguistic. ${ }^{6}$ If viable, (4) might be made compatible with the weaker interpretation of anti-individualism by restricting deference-dependence to cases in which subjects have attitudes towards a content in this weaker but not merely linguistic sense. However, one may doubt the viability of any such a notion of having an attitude towards a content containing a concept. Neither Peacocke's writings, nor Burge's provide a basis on which to construe any such notion. They never introduce a distinction between having attitudes towards a content containing a concept and possessing a concept. Unsurprisingly then, they use these expressions interchangeably (e.g. in the presentation of the Peacockean Principle of Dependence quoted above or when Burge claims that the arthritis-arguments bear on having thoughts $(2007 \mathrm{~b}$, p. 156) and also concept possession (2003, p. 308)). Even if we were to put exegetical considerations to one side, there are independent reasons to doubt the bona fide character of the propounded notion. Crucially, one such notion would suggest that the soundness of attributions of attitudes towards a content containing a concept capture a way the subject thinks of a subject matter that goes beyond mere conditions of word usage but also leaves undetermined what concepts a subject possesses. But this involves a fundamental opacity of ways of thinking in the relevant cases. What would be, for instance, the way of thinking that Bert would be using when correctly attributed a thought containing arthritis if not the way of thinking attached to the concept arthritis? In short, we seem to have exegetical and conceptual reasons to impugn, at least initially, the viability of any distinctive notion of having attitudes towards contents containing a concept $C$ beyond the ones already considered.

\section{Public Concepts}

The cases examined so far show that (4) is too strong for concept possession. Implicit conceptions, the concepts of the layman and antiindividualism all pose significant challenges to the necessity of (4). However, this thesis is also too weak: It yields possession of concepts when we would judge there is not. This we can see by reflecting on the consequences of (4) in the right to left direction: for any concept $C$ for which I might have full knowledge of the condition for something to fall under it, I must possess it. So interpreted, (4) is problematic because we typically attribute possession of $C$ only if

\footnotetext{
${ }^{6} \mathrm{I}$ thank a referee for this journal for bringing this line of reply to my attention.
} 
$C$ is publicly shareable. As Fodor (1998, pp. 28-29) put it, publicity is one of the non-negotiable constraints for any theory of concepts. People should generally turn out to possess or employ (tokens of) concepts of the same type. But how is concept publicity secured if (4) is respected?

Consider the concept animal again. Let us suppose that Sally is biologically ignorant to the extent that she disbelieves that sponges are animals. Let us assume that Sally's use of the word "animal" is in all other respects exactly like that of the animal experts in our community. Does Sally possess the concept animal? That is to say, does Sally fully know the condition for something to be the semantic value of animal? Since (4) requires that she fully knows this condition, Sally seems not allowed to possess animal. As noted in Section 5, this result is problematic because, intuitively, people other than experts would seem to have access to natural kind concepts. However, the problem I would like to point out now is that, in this hypothetical case, (4) would force us (not only to deny that Sally has animal but, furthermore) to attribute to Sally possession of the concept that matches her faulty understanding of animal, say, the concept tanimal. Obviously, tanimal is a concept Sally may be said to fully understand. However, it is not a public concept. It is Sally's solipsistic concept.

This problem generalizes wildly. For every deviant understanding $U_{1}, U_{2}, U_{3}, \ldots, U_{n}$ of a given (public) concept $C$, the natural thing to say, according to (4), is that they amount to possession of a series of different concepts $C_{1}, C_{2}, C_{3}, \ldots, C_{n}$. Since people cannot fail to fully know what it is for something to be the semantic value of any of their concepts, it just follows that subjects always have the concept that completely fits their deviant understanding. ${ }^{7}$ If (4) is true, then, the number of concepts increases astonishingly with countless different understandings. The publicity of concepts is clearly out of view.

There are some cases for which condition (4) would seem to work just fine in providing public concepts. These cases are the ones in which some restriction concerning reference might be said to be decisive. This is one of the roles that Peacocke assigns to what he calls a Determination Theory of concepts, that is to say, a theory that, for

${ }^{7}$ This is an elaboration of a point already advanced by Higginbotham (1998) in terms of conceptions. Higginbotham's main contention in that paper is that, if concept-individuating possession conditions are epistemic (i.e. require some kind of reference-determining knowledge), we cannot make sense of subject's having an inadequate conception of a concept (cf. Higginbotham 1998, pp. 155-156). 
any $C$, accounts for how semantic value is determined from $C$ 's possession condition (Peacocke 1992, p. 17). There are different ways in which a Determination Theory of $C$, according to Peacocke, would be of use to yield public $C$ s. The most important is probably the identification of genuine concepts. According to Peacocke, "alleged concepts for which there is no Determination Theory are not, under this approach, regarded as being genuine concepts at all" (Peacocke 2008, p. 46). Spurious or non-genuine concepts, such as Prior's celebrated case of tonk, are those for which there is no Determination Theory available. Note that this does nothing against the foregoing considerations. The concept tanimal has a perfectly definite semantic value. There is nothing that would prevent tanimal from having a satisfactory Determination Theory.

At one point Peacocke suggests that a Determination Theory has a regulative role in another sense. The Determination Theory serves to rule out possession conditions for a given concept but not because it is a spurious concept. Rather, these are cases in which "we know that the semantic value of a certain concept has a property and we use this fact to rule out all accounts in which the semantic value fixed in accordance with determination theory does not have this property" (Peacocke 1992, p. 20). This regulative role is, please note, of no service in ruling out tanimal as a concept Sally possesses. We know that the semantic value of tanimal is not the semantic value of animal. Loosely speaking, the semantic value of tanimal is the semantic value of animal minus the phylum porifera. This semantic value is not problematic as a semantic value of tanimal (though it certainly is as a semantic value of animal). There does not seem to be anything inappropriate in the semantic value of tanimal, apart from the fact that it is a semantic value of a hardly public concept.

The following restriction may be precisely what the defender of (4) is seeking: Conditions on possession of $C$ are only acceptable if the corresponding Determination Theory of $C$ yields the semantic value of a public shareable concept. Without further ado, however, such a restriction would seem to simply concede the point at issue. The point is that (4) makes the publicity of concepts mysterious. Deliberately restricting its application to cases of public concepts does nothing to alleviate this worry.

Finally, the advocate of (4) may try to appeal to a would-be distinction between having attitudes towards contents containing a concept and possessing the concept in order to suggest that one need not claim that subjects possess any concepts beyond attribution of attitudes with contents containing the concepts. As mentioned above 
(Section 6), one may raise serious concerns about the viability of a notion of having attitudes towards a content containing a concept that does not collapse into a merely linguistic notion concerning the truth conditions of belief reports or a way of thinking captured by the genuine possession and employment of a concept. However, even if one were to grant the availability of such a notion, note that it does nothing to arrest the worry about the publicity of concepts. For publicity only bears upon the question of what concepts a subject and the rest of her community possess. But, on the proposed objection, there are no concepts, say, Sally may safely be said to possess on the basis of one's attributions of thoughts containing animal, and hence no way of accounting for the fact that, intuitively, whatever concepts Sally is using in thinking about animals must typically be the same as the concepts possessed by the rest of her community.

\section{Where to Go: The Determination Challenge}

Taken in isolation, each objection here presented is certainly not incontestable. Their combination seems to me however to offer an insurmountable case for the falsity of (4). Since (4) is in effect an articulation of (1), the foregoing considerations also render (1) false.

There are various paths theorists might wish to follow once the falsity of (4) is acknowledged. A full examination of the possibilities escapes the scope of this already long paper. However, I would like to show, by way of conclusion, that one straightforward sort of reaction will not do, at least not within a roughly Peacockean framework of the sort we have been considering. I will also offer some considerations to the effect that the falsity of (4) poses a challenge to any theory of concept possession.

The target straightforward reaction consists of replacing (4) by $\left(4^{\prime}\right)$ :

$\left(4^{\prime}\right)$ For $S$ to meet the conditions for possessing $C$ is for $S$ to sufficiently know what it is for something to be the semantic value of $C$ (or the fundamental reference rule for $C$ ).

$\left(4^{\prime}\right)$ may prompt the impression that a minor modification of Peacockean theory may be enough for dealing with the cases of misunderstanding so far considered. Note however that $\left(4^{\prime}\right)$ expresses the idea, just like (4), that possession conditions are understanding conditions (when understanding is interpreted as knowledge of content, see Section 1). It follows from (4'), therefore, that possession conditions 
cannot fully individuate a concept. (4') makes room for the possibility of possession conditions corresponding to partial understanding. Since understanding is partial in these cases, the target conditions can individuate concepts only partially. In other words, if $\left(4^{\prime}\right)$ is true, (2) - viz. the thesis that possession conditions individuate conceptsis automatically false. No doubt, one might try to substitute (2) by some other principle. But then, the serious consideration of cases of misunderstanding leads to no minor changes in Peacocke's account. For (2) is, needless to say, the building block of the approach to concepts via concept possession.

In general, if $S$ possesses a concept $C$ which $S$ does not understand fully, then the possession conditions for $C$ do not individuate $C$ (Verdejo and de Donato 2015, §2). To illustrate, consider the concept sofa. Let us assume, for the sake of the argument, that the knowledge of the condition for something to fall under sofa which is sufficient for possessing sofa is knowledge that sofas are objects made or meant for seating with an upholstered back and seat. The problem is that this condition does not individuate sofa any more than it individuates, say, chair, armchair, divan or stroller. For these all might be said to share with sofa the mentioned condition for something to fall under the concept. This problem can be easily replicated for any propounded condition on possession of a concept which is a condition on partial understanding. If $\left(4^{\prime}\right)$ holds and our account of concepts is in terms of concept possession then it would seem that concept individuation is undeniably underdetermined. This is what we can call the determination challenge in the theory of concept possession, namely, the challenge of fully determining concept individuation from concept possession when conditions for concept possession are only conditions for partial understanding.

The determination challenge is in a sense double. It not only involves a challenge with respect to the full individuation of concepts once possession conditions are given-such as the possession conditions for sofa given above. It also involves a challenge with respect to the determination of possession conditions themselves. Let us assume that $S$ misuses a term, say "sofa", to designate an object, say a chair. Suppose that "sofa" is commonly associated with the concept sofa. Suppose further that $S$ is rational, conditions are normal and $S$ 's misuse does not depend on the lack of specific empirical information. If full understanding is in order, and if $S$ is systematic in his misuse, it seems clear that $S$ "s misuse of "sofa" entails that $S$ lacks sofa or else that $S$ employs a concept different from sofa. No such thing follows if, on the contrary, there is only partial understanding involved. 
If there is partial understanding, the question arises as of whether $S$ possesses sofa. From this point of view, the underdetermination affects possession itself. The challenge now is the challenge of determining how much error is actually compatible with possession. The conditions sufficient for possession are themselves underdetermined.

Nothing I have said here suggests that the determination challenge cannot be met and, in a sense, the moral drawn here for the theorist of concept possession is more optimistic than suggested elsewhere (cf. Verdejo and de Donato 2015). Provided that we do not give up on the assumption that possession conditions are or determine epistemologically construed understanding conditions, what we seem to need in order to meet the challenge is to articulate such conditions for understanding in ways that link up with a particular concept-individuating subject matter even in cases in which subjects have only partial understanding. It is, however, too early in the day to settle whether such articulation of concept understanding is forthcoming or not.

\section{Conclusion}

There are probably many aspects of the phenomenon of partial understanding that are yet to be addressed and await further exploration in the philosophy of mind. In this piece, I have argued that (4), as a precise articulation of (1), is presumably false for a significant number of concepts. This uncovers the need for a deep revision of theories that rely on accounts in terms of concept possession. It remains to be seen, however, whether this revision is possible. If the above considerations are on the right track, it would at least require facing the challenge to fully determine concept individuation and possession for partially understood concepts. ${ }^{8}$

\section{REFERENCES}

Bealer, G., 1998, "Concept Possession", Philosophical Issues, vol. 9, pp. 331-338.

${ }^{8}$ I would like to thank Xavier de Donato and Christopher Peacocke for their inspirational feedback on this set of issues, as well as two anonymous referees for very insightful comments on an earlier draft of this paper. This research has been supported by the Secretary for Universities and Research of the Department of Economy and Knowledge (Government of Catalonia) as well as the Ministry of Economy and Competitiveness (Government of Spain) and the European Union through the research projects FFI2016-80588-R and FFI2015-63892-P (MINECO, AEI/FEDER, EU). 
Boghossian, P., 1992, "Externalism and Inference", Philosophical Issues, vol. 2, pp. 11-37.

Brown, J., 2004, Anti-Individualism and Knowledge, The MIT Press, Cambridge, Mass.

— , 2000, "Critical Reasoning, Understanding, and Self-Knowledge", Philosophy and Phenomenological Research, vol. 61, no. 3, pp. 659676.

Burge, T., 2007a, Foundations of Mind. Philosophical Essays, vol. 2, Oxford University Press, Oxford.

— 2007b, "Postscript to 'Individualism and the Mental", in Burge 2007a, pp. 151-191.

— 2003, "Social Anti-Individualism, Objective Reference", reprinted in Burge 2007a, pp. 307-315.

— 1990, "Frege on Sense and Linguistic Meaning", reprinted in T. Burge (ed.), Truth, Thought, Reason. Oxford University Press, Oxford, pp. 242-270.

- 1988, "Individualism and Self-Knowledge", Journal of Philosophy, vol. 85, no. 11, pp. 649-663.

— 1986, "Intellectual Norms and the Foundations of Mind", Journal of Philosophy, vol. 83, no. 12, pp. 697-720.

— 1979, "Individualism and the Mental", reprinted in Burge 2007a, pp. $100-150$.

Davis, W., 2008, "Thought Structure, Belief Content, and Possession Conditions", Acta Analitica, vol. 23, no. 3, pp. 207-231.

- 2005a, "Concept Individuation, Possession Conditions, and Propositional Attitudes", Noûs, vol. 39, no. 1, pp. 140-166.

- 2005b, "Concepts and Epistemic Individuation", Philosophy and Phenomenological Research, vol. 70, no. 2, pp. 290-325.

Fodor, J.A., 2008, LOT 2: The Language of Thought Revisited, Oxford University Press, Oxford.

— 2004, "Having Concepts, a Brief Refutation of the XXth Century", Mind and Language vol. 19, no. 1, pp. 29-47.

- 1998, Concepts. Where Cognitive Science Went Wrong, Oxford University Press, Oxford.

Frege, G., 1914, "Logik in der Mathematik", in H. Hermes, F. Kambartel, and F. Kaulbach (eds.), Nachgelassene Schriften, Felix Meiner, Hamburg, 1969 (translated as "Logic in Mathematics" by P. Long and R. White, in Posthumous Writings, Basil Blackwell, Oxford, 1979, pp. 201250.)

Goldberg, S., 2009, "Experts, Semantic and Epistemic", Noûs, vol. 43, no. 4 , pp. 581-598.

—, 2002 , "Do Anti-Individualistic Construals of Propositional Attitudes Capture the Agent's Conceptions?", Noûs, vol. 36, no. 4, pp. 597-621.

Higginbotham, J., 1998, "Conceptual Competence", Philosophical Issues, vol. 9, pp. 149-162. 
Martí, G., 1998, "The Significance of the Distinction between Concept Mastery and Concept Possession", Philosophical Issues, vol. 9, pp. 163-167. Peacocke, C., 2014, The Mirror of the World, Oxford University Press, Oxford.

—_, 2012, "Concepts", in G. Russell and D. Graff Fara (eds.), The Routledge Companion to the Philosophy of Language, Routledge, London, pp. 221-230.

- 2008 , Truly Understood, Oxford University Press, Oxford.

, 2004, "Interrelations: Concepts, Knowledge, Reference and Structure", Mind and Language, vol. 19, no. 1, pp. 85-98.

—_ 2000, "Explaining the A Priori: The Program of Moderate Rationalism", in P. Boghossian and C. Peacocke (eds.), New Essays on the A Priori, Oxford University Press, Oxford, pp. 255-285.

- , 1999, Being Known, Oxford University Press, Oxford.
,- 1998, "Implicit Conceptions, Understanding and Rationality", Philosophical Issues, vol. 9, pp. 43-88.

—_ 1997, "Concepts without Words", in R. Hecke (ed.), Language, Thought, and Logic: Essays in Honour of Michael Dummett, Oxford University Press, Oxford, pp. 1-33.

- 1992, A Study of Concepts, The MIT Press, Cambridge, Mass.

_- 1989, "Possession Conditions: A Focal Point for Theories of Concepts", Mind and Language, vol. 4, nos. 1-2, pp. 51-56.

- 1983 , Sense and Content: Experience, Thought and Their Relations, Oxford University Press, Oxford.

Rey, G., 1998, "What Implicit Conceptions Are Unlikely to Do", Philosophical Issues, vol. 9, pp. 93-104.

Roca-Royes, S., 2010, "Modal Epistemology, Modal Concepts and the Integration Challenge", Dialectica, vol. 64, no. 3, pp. 335-361.

Schroeter, L., 2008, "Why Be an Anti-Individualist?", Philosophy and Phenomenological Research, vol. 74, no. 1, pp. 105-141.

Verdejo, V.M., 2016, "Understanding and Disagreement in Belief Ascription", International Journal of Philosophical Studies, vol. 24, no. 2, pp. 183-200.

Verdejo V.M. and X. de Donato, 2015, "Partial Understanding and Concept Possession: A Dilemma", Ratio, vol. 28, no. 2, pp. 153-162.

Wedgwood, R., 2007, The Nature of Normativity, Oxford University Press, Oxford.

Wikforss, A., 2008, "Self-Knowledge and Knowledge of Content", Canadian Journal of Philosophy, vol. 38, no. 3, pp. 399-424.

Received: August 27, 2015; revised: February 21, 2018; accepted: April 12, 2018. 